\title{
Communication
}

\section{Properties of Gasoline Stored in Various Containers}

\author{
Cheol-Hwan Jeon ${ }^{1,2}$, Cheon-Kyu Park ${ }^{1}$, Byung-Ki Na ${ }^{2, *}$ and Jae-Kon Kim ${ }^{1, *}$ \\ 1 Research Institute of Petroleum Technology, Korea Petroleum Quality \& Distribution Authority, \\ Cheongju 28115, Korea; chjeon@kpetro.or.kr (C.-H.J.); kpqi1176@kpetro.or.kr (C.-K.P.) \\ 2 Department of Chemical Engineering, Chungbuk National University, Cheongju 28644, Korea \\ * Correspondence: nabk@chungbuk.ac.kr (B.-K.N.); jkkim@kpetro.or.kr (J.-K.K.); \\ Tel.: +82-43-240-7932 (B.-K.N \& J.-K.K.)
}

Received: 15 July 2017; Accepted: 29 August 2017; Published: 1 September 2017

\begin{abstract}
Recently, consumers in rural areas have complained about the reduction of the octane number for gasoline stored in storage containers made of polyethylene (PE) in Korea. In addition, problems have been found in gasoline that has not been used for a long time in dual-fueled cars that use liquefied petroleum gas and gasoline at the same time. The reduction of the octane number has caused problems in the quality of fuels. To understand the fuel quality problems, the fuel properties of gasoline for automobiles were investigated in this study by storing gasoline for a long time in various simplified storage containers (tin-coated steel, $\mathrm{PE}$, and polyethylene terephthalate (PET)) in a laboratory scale. For the four months of the storage period, the storage containers were kept indoors and outdoors to monitor the research octane number ( $R O N)$, vapor pressure, oxidation stability, and the content of all the components to evaluate the fuel properties. In addition, the surfaces of containers were analyzed by scanning electron microscope (SEM) images of the PE storage containers that were kept outdoors under extremely harsh conditions. Depending on the storage period, some of the PE storage containers kept indoors and outdoors failed to satisfy the specification of quality standards of the gasoline as the samples with high octane numbers and low boiling points evaporated. In addition, the octane number of the gasoline in PE storage container stored indoors decreased as the content of $n$-paraffin and olefins having low boiling point components decreased during the storage period. The surface analysis of the PE storage containers kept indoors showed that the gasoline permeated into the surface of the containers. In this study, it has been showed that tin-coated steel material storage containers for gasoline storage are less affected by external influences than PE material storage containers and thus are more advantageous for maintaining stable fuel quality.
\end{abstract}

Keywords: automobile gasoline; fuel specification; fuel storage; fuel container

\section{Introduction}

Gasoline is a mixture of $\mathrm{C}_{4}$ to $\mathrm{C}_{12}$ hydrocarbon compounds containing single or double bonds. This petroleum fraction distills in the temperature range 30 to $220^{\circ} \mathrm{C}$ [1]. It is very dangerous because it can easily evaporate at room temperature and atmospheric pressure, is highly inflammable, and becomes explosive when the volatile gas is mixed with the air. The gasoline mixture also includes a small amount of oxygenates, sulfur compounds, and nitrogen compounds. The hydrocarbon compounds in gasoline may be classified as n-paraffins, iso-paraffins, olefins, aromatic compounds, and naphthenics. The relative ratios among these five groups of hydrocarbon compounds are determined by considering the manufacturing process, the requirements of the automobile engine, and the quality standards for appropriate fuels in individual countries [1].

The gasoline for automobiles in Korea is produced by mixing straight-run gasoline, reformed gasoline, cracked gasoline, and methyl tert-butyl ether (MTBE) from refineries based on the quality 
standards for gasoline from the Petroleum and Petroleum Alternative Fuel Business Act and by adding various additives, such as antioxidants [2].

During the storage period, the hydrocarbon compounds in gasoline may cause physical or chemical changes through their reactions with oxygen in the air, resulting in a change in the fuel quality. In addition, the oxidation of the components in gasoline itself also causes deterioration of its fuel quality which affects the quality of the fuel [3]. Due to oxidation of the fuel involved in the storage, the amount of gum-which is a polymeric material produced by polymerization or condensation through oxidation-is increased, the content of olefin is decreased, the vapor pressure of the low-boiling point components is decreased by evaporation, the composition is changed, and the octane number is decreased [4-8]. After undergoing these changes, if the gasoline is used as a fuel for automobiles, the gum may be deposited in the fuel supply system, including the fuel filter and the fuel delivery line, which can cause problems at start-up and reduce vehicle performance [9].

In general, tin-coated and closed steel containers are used for long-term storage of gasoline. However, recently, some consumers in rural areas have complained about the reduction of the octane numbers for gasoline stored in storage containers made of plastic in Korea. This is because the plastic containers are cheaper than tin-coated steel containers and can be purchased easily. Octane numbers are among the most important physico-chemical parameters to be evaluated because they are directly related to the performance and power of the engine. The issues of fuel quality have been raised in the gasoline that has not been used for a long time in dual-fueled cars that use liquefied petroleum gas and gasoline at the same time. Complaints have also been made about the degradation of gasoline quality depending on the fuel storage environment and about the degradation of the quality of gasoline stored in plastic containers. Reports have suggested that the hydrocarbon compounds in gasoline may be permeated into plastic materials $[10,11]$. However, the effect of the adsorption on the fuel quality has not been scientifically proven, resulting in continued difficulties in quality control.

Automobile fuel tanks are made of plastic material to lighten weight and used of multilayer using high-density PE (HDPE), regrind, Ethylene-Vinyl Alcohol (EVOH) However, the material of the automobile fuel tank is not the object and it was aimed to observe the change of the fuel quality according to the material of the storage container rather than the material of the automobile parts. In this study, the variation of the long-term storage fuel quality of gasoline for automobiles circulated in Korea was investigated at a laboratory scale. The simplified storage containers used in the present study were prepared by using plastic materials (PE and PET). During the storage period (four months), the quality of the gasoline for automobiles was evaluated by measuring the major factors representing the quality characteristics, including the octane number, distillation characteristics, vapor pressure, oxidation stability, and component contents (aromatic compounds, olefin, paraffin, and naphthene). The surface characteristics of the storage containers were also analyzed after the storage period.

\section{Materials and Methods}

\subsection{Materials}

To investigate the effect of the long-term storage of automobile gasoline currently circulated in Korea, gasoline was purchased from a gas station. A tin-coated steel storage container (CAN), which is frequently used to store gasoline and petroleum products was employed. In addition, the long-term storage properties were also evaluated by purchasing plastic storage containers produced and used in Korea Polyethylene (PE) storage containers (2 and $20 \mathrm{~L}$ ) were purchased from Younkyung chemical company (Gimpo, Korea) and Dongbang plastic company (Gimpo, Korea), while PET (2 L) storage containers were purchased from Dongbang plastic company in Table 1. All storage containers are closed by a sealing lid during storage period. In the sampling, gasoline stored in each small storage containers $(1,1.5$, and $2 \mathrm{~L})$ was immediately analyzed, and the large storage container $(20 \mathrm{~L})$ was closed after the sampling of the analysis sample. Indoor storage was used because most petroleum products are stored indoors. However, the storage characteristics of PE storage containers were 
also evaluated outdoors under harsh conditions to clearly investigate the quality variation of $\mathrm{PE}$ storage containers. This is because complaints have been made by consumers. The experiment for investigating the long-term storage characteristics of gasoline was performed for four months. During the storage period, the samples were equipped with a fire wall and a fire extinguisher for safety. About $3000 \mathrm{~mL}$ of the sample was taken for analysis, and the variation of the properties was investigated by measuring the octane number and vapor pressure at an interval of 15 days in Table 1 . The distillation characteristics and oxidation stability were measured at an interval of 30 days. During the period of storing the gasoline sample, the average temperature of the external environment ranged from about $14{ }^{\circ} \mathrm{C}$ to $25{ }^{\circ} \mathrm{C}$ with a maximum temperature of $31^{\circ} \mathrm{C}$, and the relative humidity was in the range of $62 \%$ to $81 \%$. According to the Petroleum and Petroleum Alternative Fuel Business Act in Korea, the items included in Article 1 of the "Quality Standard for Autotmobile Gasoline", Ministry of Trade, Industry and Energy Notice No. 2016-20 [2], as well as the moisture content and density were also analyzed. Table 2 shows the quality evaluation items and the testing methods. The results of all tests were three arithmetic averages, which met the repeatability presented in each test method, as shown in Table 2.

Table 1. Sample containers and storage areas.

\begin{tabular}{ccccc}
\hline No. & Storage Container $^{\mathbf{1}}$ & Capacity (L) & Number of Samples & Storage Area \\
\hline 1 & CAN & 1.5 & 20 & Indoor \\
2 & YK-PE & 2 & 15 & Indoor \\
3 & YK-PE & 20 & 2 & Indoor \\
4 & YK-PE & 2 & 15 & Outdoor \\
5 & DB-PE & 2 & 15 & Indoor \\
6 & DB-PE & 20 & 2 & Indoor \\
7 & DB-PET & 1 & 30 & Indoor \\
\hline
\end{tabular}

${ }^{1}$ CAN: tin-coated steel containers, YK-PE: polyethylene containers, DB-PET: polyethylene terephalate containers.

The physico-chemical properties of automobile gasoline were analyzed according to the gasoline quality standards of Korea [2]. Table 2 shows physicochemical properties and test methods in sample gasoline. The gasoline was purchased from a gas station directly managed by a Korean refinery company and used as a sample. The purchased gasoline satisfied Korea's quality standards for gasoline as shown in Table 2. Therefore, the values of the sample for fuel quality aspects-including the octane number, distillation characteristics, vapor pressure, oxidation stability, and component contents were established as the initial values for the monitoring evaluation of the fuel properties during the storage period.

Table 2. Test methods and fuel quality of automobile gasoline in the experiments.

\begin{tabular}{|c|c|c|c|c|}
\hline & roperties & Specification & Value & Test Method \\
\hline \multicolumn{2}{|c|}{ Octane No. (RON) } & $91-94$ & 92.8 & ASTM D2699 \\
\hline \multirow{5}{*}{ Distillation } & $\mathrm{T} 10\left({ }^{\circ} \mathrm{C}\right), \max$ & 70 & 53.1 & \multirow{5}{*}{ ASTM D86 } \\
\hline & $\mathrm{T} 50\left({ }^{\circ} \mathrm{C}\right), \max$ & 125 & 82.2 & \\
\hline & $\mathrm{T} 90\left({ }^{\circ} \mathrm{C}\right), \max$ & 170 & 157.3 & \\
\hline & $\operatorname{FBP}\left({ }^{\circ} \mathrm{C}\right), \max$ & 225 & 203.5 & \\
\hline & Residue, vol \%, max & 2.0 & 1.0 & \\
\hline \multicolumn{2}{|c|}{ Water and sediment (vol \%), $\max$} & 0.01 & 0.005 & ASTM D2709 \\
\hline \multicolumn{2}{|c|}{ Copper corrosion $\left(50^{\circ} \mathrm{C}, 3 \mathrm{~h}\right), \max$} & 1 & $1 \mathrm{a}$ & ASTM D130 \\
\hline \multicolumn{2}{|c|}{ Vapor pressure $\left(37.8^{\circ} \mathrm{C}, \mathrm{kPa}\right)$} & 44-82 (summer: 44-60, winter: 44-96) & 64.8 & ASTM D5191 \\
\hline \multicolumn{2}{|c|}{ Oxidation stability (min), min } & 480 & 480 & ASTM D525 \\
\hline \multicolumn{2}{|c|}{ Washed gums $(\mathrm{mg} / 100 \mathrm{~mL}), \max$} & 5 & 0.01 & ASTM D381 \\
\hline \multicolumn{2}{|c|}{ Sulfur content $(\mathrm{mg} / \mathrm{kg}), \max$} & 10 & 6.03 & ASTM D5453 \\
\hline
\end{tabular}


Table 2. Cont.

\begin{tabular}{|c|c|c|c|}
\hline Properties & Specification & Value & Test Method \\
\hline Color & Yellow & Yellow & - \\
\hline Lead content $(\mathrm{g} / \mathrm{L}), \max$ & 0.013 & 0.001 & ASTM D3237 \\
\hline Phosphorus content (g/L), max & 0.0013 & 0.0001 & ASTM D3231 \\
\hline Aromatic content (vol \%), max & $22(19)$ & 18.96 & JIS K 2536-2 \\
\hline Benzene content (vol \%), $\max$ & 0.7 & 0.52 & JIS K 2536-2 \\
\hline Olefin content (vol \%), max & $16(19)$ & 13.91 & JIS K 2536-2 \\
\hline Oxygen content (wt \%), $\max$ & 2.3 & 2.10 & JIS K 2536-2 \\
\hline Methanol content (wt \%), max & 0.1 & 0.00 & JIS K 2536-2 \\
\hline
\end{tabular}

\subsection{Analysis of Storage Gasoline and PE Surface}

To evaluate the properties of the gasoline based on the storage containers, evaluation was performed with regards to major quality standard items depending on the storage period of gasoline, which were the octane numbers, vapor pressure, oxidation stability, and total components (aromatic compounds, olefin, paraffin, and naphthene). With regard to the octane numbers, the ASTM D2699 test method was used with a CFR/F-1 engine (Waukesha CFR Engines Inc., Waukesha, WI, USA). The vapor pressure $\left(\right.$ at $\left.37^{\circ} \mathrm{C}\right)$ was analyzed according to the ASTM D5191 test method by using the 8000 model instrument (Sanhope-Seta Co., London, UK). To analyze the total components of the gasoline, the gas chromatography (GC) analyses were run on an Agilienet 7890 series GC (Agilent Technologies, Beijing, China) according to JIS K 2536-2 test method. In addition, ${ }^{1} \mathrm{H}-\mathrm{Nuclear}$ Magnetic Resonance (NMR) (Bruker DPX-300, Bruker Co., Rheinstetten, Germany) was used for analysis. The surface of the PE container after undergoing the storage period was coated with gold and then analyzed by using a scanning electron microscope (SEM, JEOL Ltd., Tokyo, Japan).

\section{Results}

\subsection{Variation of Fuel Quality Depending on Storage Containers' Type}

With regard to the fuel properties of the gasoline for automobiles depending on the storage containers in the storage period, Figure 1 shows the variation of the research octane number (RON), which is the most important indicator affecting the automobile's performance. The octane number is closely related to the molecular structures of various hydrocarbons in gasoline for automobiles: the octane number is dependent on the length and the degree of branching of carbon chains in hydrocarbons.

As shown in Figure 1, the RON for the gasoline in automobiles depending on the storage period only satisfied the specification of quality standards, as shown in Table 2, in the CAN and the PET storage containers. CAN and PET containers have better sealing systems than other containers. The octane number was decreased from the initial value by 4.0 to 18.5 for the gasoline in the PE storage containers stored indoors and outdoors, respectively. In particular, the octane number was decreased by a maximum of 18.5 in gasoline stored outdoors in the PE storage container. While the octane number was decreased by 0.2 to 0.6 in the steel CAN and the PET storage containers, respectively, the research octane number still satisfied the specification of quality standards as shown in Table 2.

To investigate how long it takes the RON of the gasoline in the PE storage containers stored outdoors exposed to fall below quality standards, the RON was measured at an interval of four days. In the case of PE container stored outdoors, the RON of gasoline sharply decreased to 90 eight days after starting storage, thereby failing to satisfy the specification of quality standards. This may change according to the photo-oxidation due to sunlight exposure and the evaporation of low-boiling point components with high RON. 
Table 3 shows the variation of distillation characteristics of gasoline depending on the storage containers' type after four months. The distillation characteristics of the gasoline satisfied the specification of quality standards in all of the storage containers' type. Figure 2 shows the variation of the vapor pressure and the oxidation stability of gasoline stored in individual storage containers over time. As shown in Figure 2a, the vapor pressure of the gasoline was decreased by 0.4 to $7.4 \mathrm{kPa}$ depending on the storage containers over time, but the vapor pressure still met the quality standard specifications. For the gasoline in PE storage containers stored outdoors, the vapor pressure drastically decreased by a maximum of $7.4 \mathrm{kPa}$ due to the sunlight exposure in comparison with other storage containers. Figure $2 \mathrm{~b}$ shows the result of the oxidation stability evaluation of gasoline, indicating that the gasoline stored in all kinds of storage containers stored indoors satisfied the quality standard specifications, but only the gasoline in PE storage containers stored outdoors did not meet the specification of quality standards. The oxidation stability decreased from the initial value over time for the gasoline in all types of storage containers stored indoors. The reduction of oxidation stability in other storage containers was about 530 to $582 \mathrm{~min}$. The order of oxidation stability for gasoline in storage containers was tin-coated steel $>$ PET $>$ indoor PE $>$ outdoor PE.

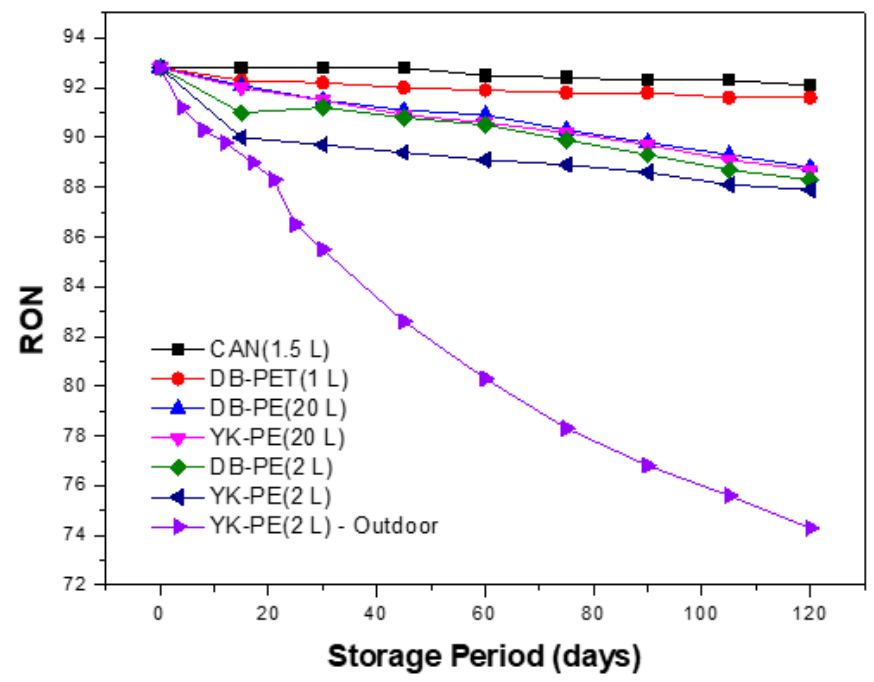

Figure 1. RON variation of gasoline stored in various containers over storage period.

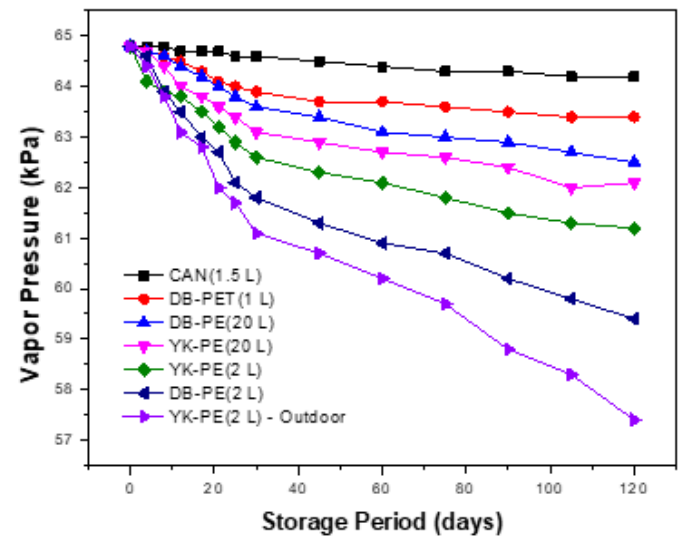

(a)

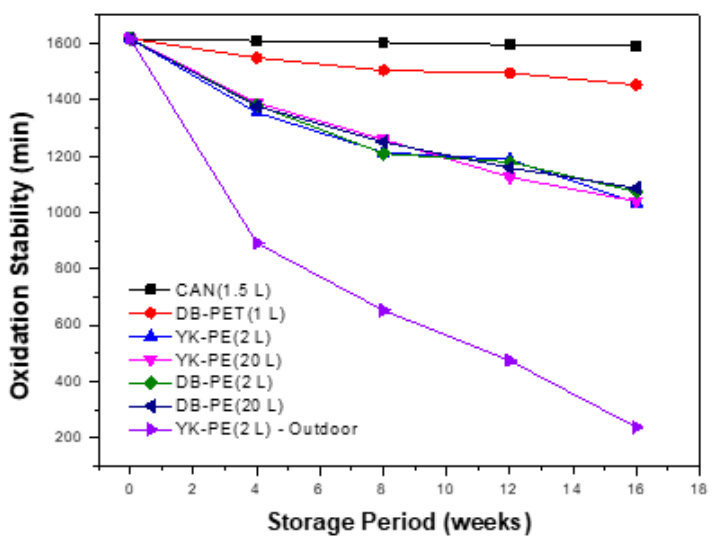

(b)

Figure 2. Vapor pressure and oxidation stability of automobile gasoline in various containers with respect to storage period: (a) variation of vapor pressure; (b) variation of oxidation stability. 
Table 3. Distillation variation of automobile gasoline in various containers after four months.

\begin{tabular}{ccccccccc}
\hline \multirow{2}{*}{ Distill. Temp. } & \multirow{2}{*}{ Initial Value } & CAN & YK-PE & YK-PE & YK-PE & DB-PE & DB-PE & DB-PET \\
\cline { 2 - 8 } & & $\mathbf{( 1 . 5} \mathbf{~})$ & $\mathbf{( 2 ~ L )}$ & $\mathbf{( 2 0 ~ L )}$ & $\mathbf{( 2 ~ L )} \mathbf{1}^{\mathbf{1}}$ & $\mathbf{( 2 ~ L )}$ & $\mathbf{( 2 0 ~ L )}$ & $\mathbf{( 1 ~ L )}$ \\
\hline T10 $\left({ }^{\circ} \mathrm{C}\right)$ & 53.1 & 52.5 & 56.4 & 52.4 & 54.9 & 54.8 & 52.6 & 53.9 \\
T50 $\left({ }^{\circ} \mathrm{C}\right)$ & 82.2 & 81.8 & 86.3 & 81.6 & 85.0 & 84.4 & 81.8 & 83.0 \\
T90 $\left({ }^{\circ} \mathrm{C}\right)$ & 157.3 & 156.5 & 159.0 & 157.1 & 158.9 & 158.1 & 156.8 & 157.1 \\
FBP $\left({ }^{\circ} \mathrm{C}\right)$ & 203.5 & 204.3 & 206.1 & 200.9 & 198.9 & 203.4 & 205.4 & 205.0 \\
\hline
\end{tabular}

Table 4 shows the analytical results of the total components of the gasoline stored in individual storage containers after four months. The component contents of the gasoline, depending on the storage containers and the storage time, were analyzed according to the JIS K 2536-2 test method based on gas chromatography (GC). This was done by analyzing the contents of aromatic compounds, olefin, paraffin, and naphthene. The component contents of the gasoline in all kinds of storage containers satisfied the specification of quality standards. However, the olefin content decreased by $1.99 \mathrm{vol} \%$ and that of $n$-paraffin by $0.88 \mathrm{vol} \%$ in the gasoline in PE storage container stored outdoors. This suggests that high octane fuel with $C_{2}$ to $C_{6}$ components, such as paraffin and olefin, may have easily evaporated from the gasoline in storage containers stored indoors or outdoors, which lowered the octane number, thus affecting the automobile's performance. Figure 3 shows that hydrocarbon reduction contents of $\mathrm{C}_{4}$ to $\mathrm{C}_{6} n$-paraffin and olefin contents were all decreased in the gasoline in PE storage containers stored outdoors after four months. In particular, the content of the $n$-butane, 2,2-dimethylpropane, 1-pentene, 2-methyl-1-butene, trans-2-pentene, cis-2-pentene, 2-methyl-2-butene decreased the most by $0.22,0.27,0.05,0.13,0.44,0.15$, and $0.51 \mathrm{vol} \%$ in comparison with the initial contents. After four months of storage, the total compositional difference of gasoline in all kinds of storage containers is a small in Table 4, but gasoline in PE storage container stored outdoor is decreased the hydrocarbons contents such as $n$-paraffins, olefins with low boiling point, and high octane number by external factors, as shown in Figure 3.

Table 4. Composition variation of automobile gasoline in various containers after four months ${ }^{1}$.

\begin{tabular}{ccccccccc}
\hline \multirow{2}{*}{ Content (vol \%) } & \multirow{2}{*}{ Initial Value } & CAN & YK-PE & YK-PE & YK-PE & DB-PE & DB-PE & DB-PET \\
\cline { 3 - 8 } & & $\mathbf{( 1 . 5} \mathbf{~ L )}$ & $\mathbf{( 2 ~ L )}$ & $\mathbf{( 2 0 ~ L )}$ & $\mathbf{( 2 ~ L )} \mathbf{~}^{\mathbf{2}}$ & $\mathbf{( 2 ~ L )}$ & $\mathbf{( 2 0 ~ L )}$ & $\mathbf{( 1 ~ L ) ~}$ \\
\hline Aromatic & 18.96 & 19.15 & 19.76 & 18.79 & 19.40 & 19.33 & 18.77 & 19.19 \\
Olefin & 13.91 & 14.04 & 12.27 & 14.02 & 11.92 & 12.90 & 13.80 & 14.01 \\
n-Parffin & 11.01 & 10.84 & 10.63 & 10.94 & 10.13 & 10.70 & 10.97 & 10.92 \\
iso-Paraffin & 38.86 & 38.93 & 39.87 & 39.12 & 40.50 & 39.78 & 39.05 & 38.82 \\
Naphtene & 6.79 & 6.99 & 7.20 & 6.84 & 6.88 & 7.04 & 6.79 & 6.86 \\
\hline
\end{tabular}

${ }^{1}$ PONA analysis by JIS K $2536-2$ test method. ${ }^{2}$ Stored outdoors.

In addition, ${ }^{1} \mathrm{H}-\mathrm{NMR}$ instrument was used to analyze the variation of the contents of olefin and paraffin in the gasoline in PE storage containers stored in the outdoor. Figure 4a shows ${ }^{1} \mathrm{H}-\mathrm{NMR}$ spectrum of the initial gasoline, and Figure $4 \mathrm{~b}$ shows ${ }^{1} \mathrm{H}-\mathrm{NMR}$ spectrum of the gasoline after four months. The ${ }^{1} \mathrm{H}-\mathrm{NMR}$ analysis showed that the olefin content ranged from 5.44 to $4.67 \mathrm{ppm}$ of vinylic proton in olefinic hydrocarbon components and the paraffin content ranged from 2.63 to $0.83 \mathrm{ppm}$ of the alkane proton. It showed that the contents of olefin and paraffin were decreased in comparison with the initial values, as shown in Figure 4. 


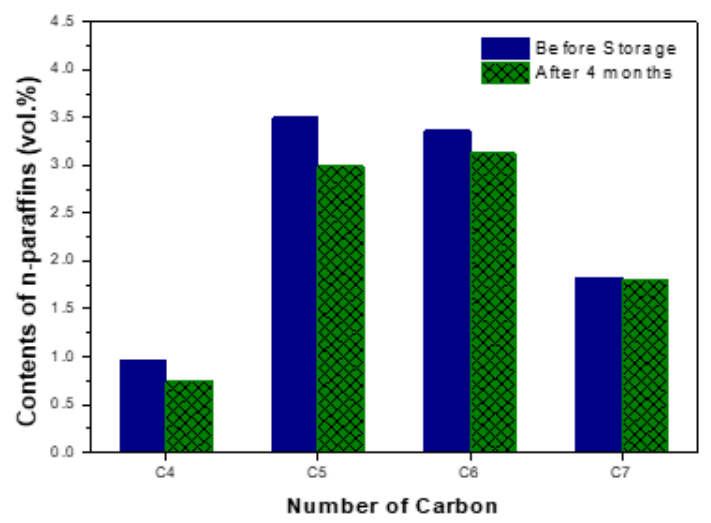

(a)

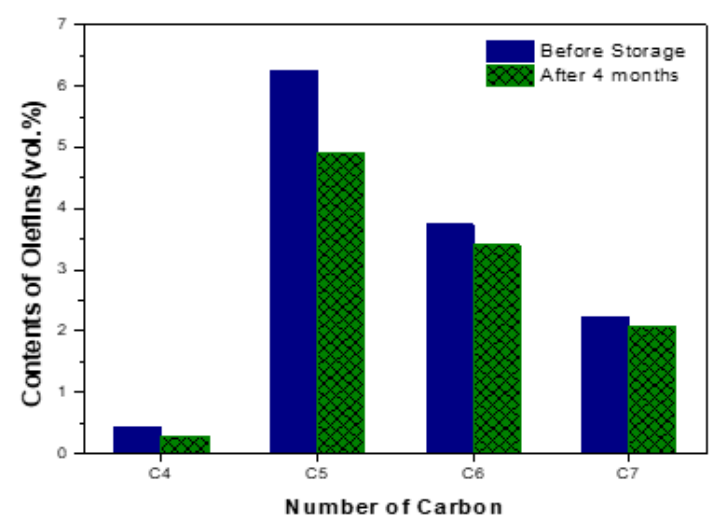

(b)

Figure 3. Composition variation of in PE container outdoor after four months: (a) variation of n-paraffins; (b) variation of olefins.

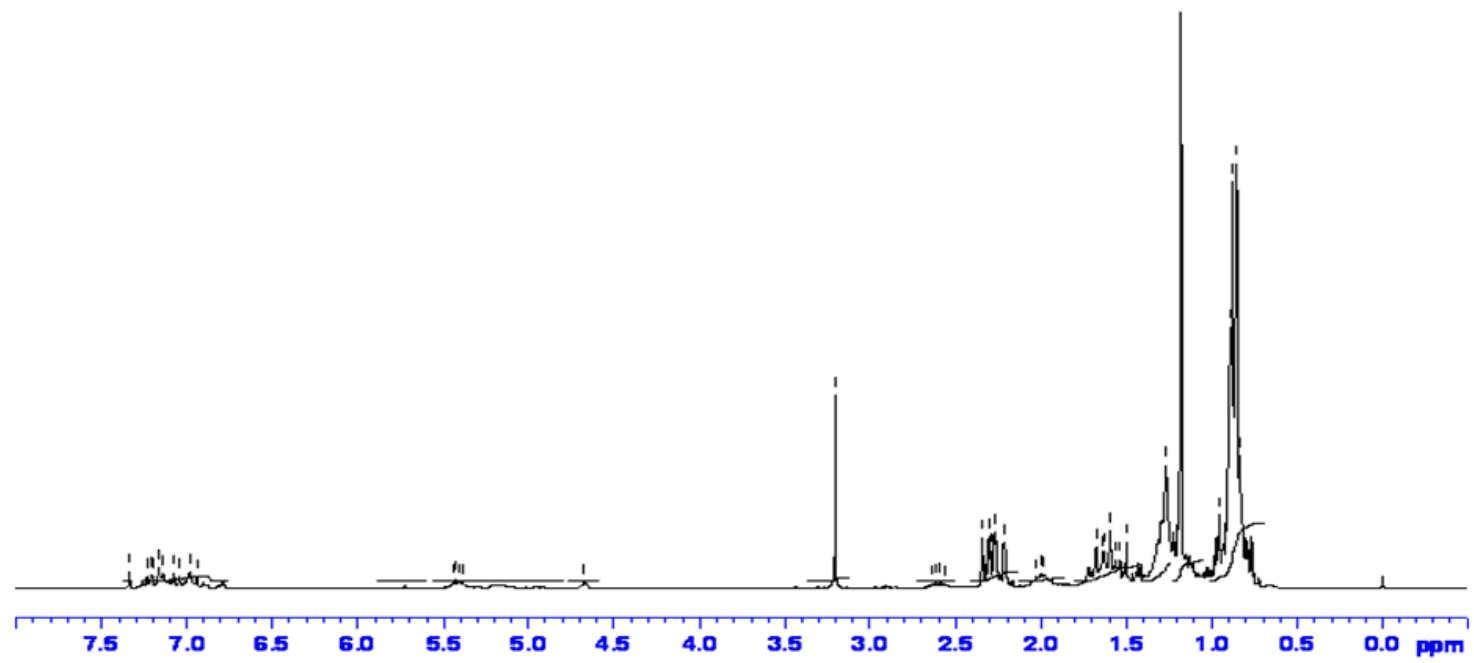

(a)

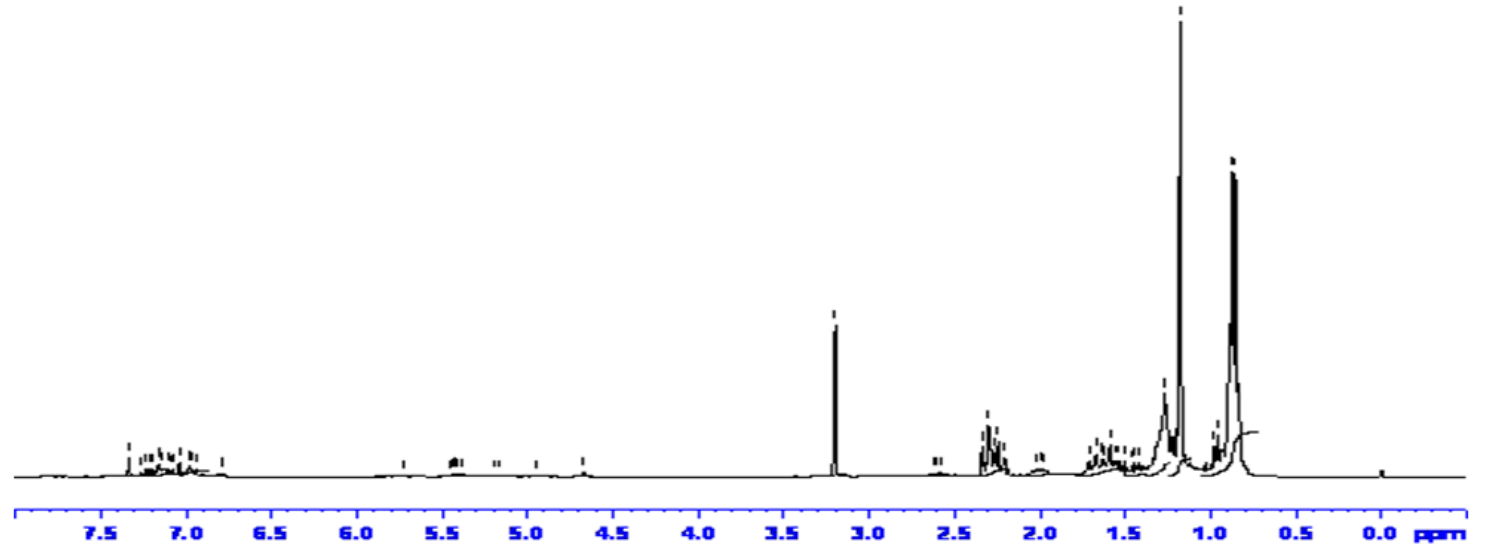

(b)

Figure 4. ${ }^{1} \mathrm{H}-\mathrm{NMR}$ spectra of gasoline: (a) gasoline before storage; (b) gasoline in PE storage container stored outdoor after four months. 


\subsection{Analysis of the Surfaces of Storage Containers}

The surfaces of the PE containers stored outdoors changed from an initial white color to yellow after a storage period of four months. After the storage period, the surfaces of the PE containers stored outdoors were analyzed by using SEM. SEM micrographs of fracture surfaces of PE containers stored outdoors are presented in Figure 5. Figure $5 c, d$ are fractured surfaces of PE containers stored outdoors for four months. This further indicates permeation of gasoline into PE surfaces, compared with the PE surface in Figure 5a before storage. As a result, the components of the gasoline permeated the surface of the PE storage container stored outdoors over time.

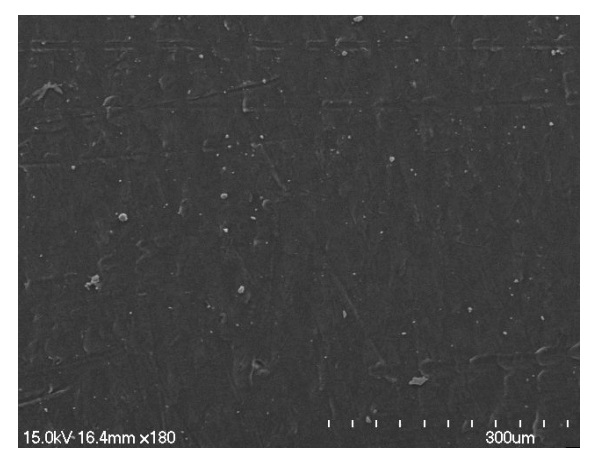

(a)

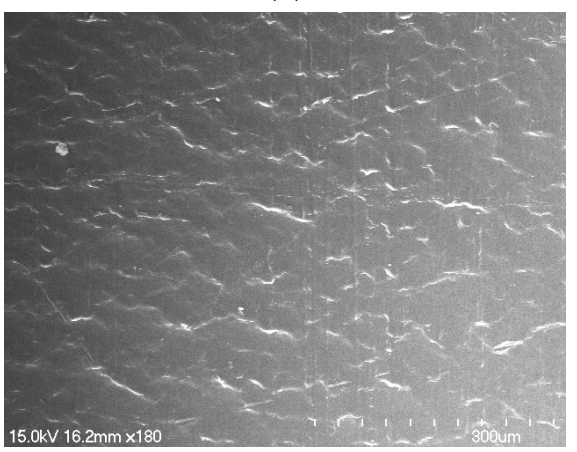

(c)

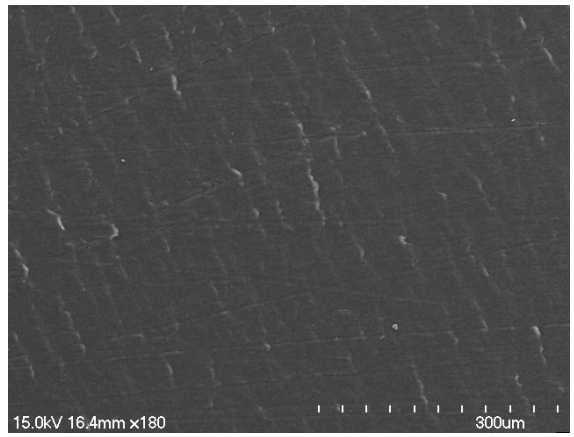

(b)

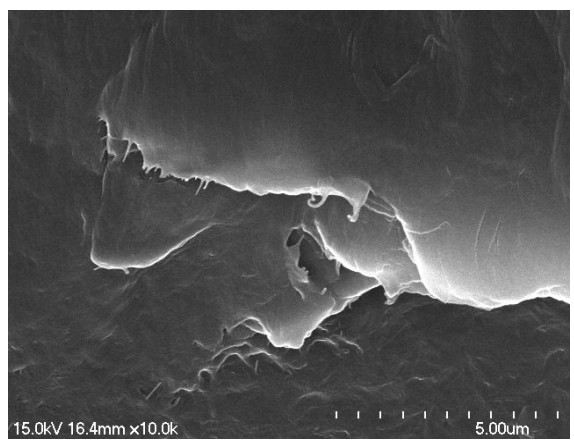

(d)

Figure 5. SEM images of the fractured surface of PE containers storage outdoors: (a) initial $(300 \mu \mathrm{m})$; (b) after two months $(300 \mu \mathrm{m})$; (c) after four months $(300 \mu \mathrm{m})$; (d) after four months $(5 \mu \mathrm{m})$.

\section{Conclusions}

In this study, the following conclusions were obtained by evaluating the fuel physiochemical properties of gasoline for automobiles stored indoors and outdoors by using various kinds of storage containers (steel, PE, and PET) at a laboratory scale for a storage period of four months. Among the fuel quality items for gasoline depending on the storage containers and the storage time, RONs of the gasoline in all the PE storage containers stored indoors and outdoors failed to satisfy the specification of Korean quality standards after the storage period.

However, the gasoline stored in all the steel containers and the PET storage container satisfied the RON specification. The oxidation stability of gasoline stored in all the plastic storage containers failed to satisfy the quality standards. The total component analysis of the gasoline stored in the individual storage containers showed that all the quality standards were satisfied. However, the olefin content decreased by $1.99 \mathrm{vol} \%$ and that of $n$-paraffin decreased by $0.88 \mathrm{vol} \%$ in the gasoline in PE storage containers stored outdoors. When gasoline is stored indoors or outdoors for a long time, the gasoline components with high RONs may be oxidized or evaporated, which affects the gasoline's fuel quality. The analysis of the surface of the PE storage container stored outdoor showed that the components of the gasoline permeated the surface over time. In this study, it has been shown that tin-coated steel 
material storage containers for gasoline storage are less affected by external influences than PE storage containers, and thus are more advantageous for maintaining stable fuel quality.

Acknowledgments: This work was supported by the internal project of Korea Petroleum Quality \& Distribution Authority and Ministry of Trade, Industry \& Energy (MOTIE) under the works of technology development program, study on development of optimization for domestic application improvement of E3 level transport Biofuels (No. 20163010092160).

Author Contributions: Cheol-Hwan Jeon, Cheon-Kyu Park designed the study, and performed the experiments, and wrote the paper. Jae-Kon Kim and Byung-Ki Na provided important comments on the approach to samples analysis and revised the paper.

Conflicts of Interest: The authors declare no conflict of interest.

\section{References}

1. Oliveria, F.S.; Teixerira, L.S.G.; Araújo, M.C.U.; Korn, M. Screening analysis to detect adulterations in Brazilian gasoline samples using distillation curves. Fuel 2004, 83, 917-923. [CrossRef]

2. Ministry of Trade, Industry and Energy (MOTIE). Quality Standard for Autotomobile Gasoline. 2017. Available online: http://www.motie.go.kr/motie/ms/nt/gosi/bbs/bbsView.do?bbs_seq_n=62709\&bbs_ cd_n (accessed on 11 June 2017).

3. Min, K.I.; Yim, E.S.; Jung, C.-S.; Kim, J.-K. Study on the characterization of oxidative degradation of automotive gasoline. Korean Chem. Eng. Res 2013, 51, 250-256. [CrossRef]

4. Zhong, B.; Zheng, D. A chemical mechanism for ignition and oxidation of multi-component gasoline surrogate fuels. Fuel 2014, 128, 458-466. [CrossRef]

5. Burkhan, O. Change in the properties of gasoline in storage in underground tanks. Chem. Technol. Fuels Oils 2008, 44, 301-305. [CrossRef]

6. Walters, E.L.; Yabroff, D.L.; Minor, H.B. Correlation of Predicted and Observed Storage Stability of Cracked Gasoline. Ind. Eng. Chem. 1948, 40, 423-428. [CrossRef]

7. Nagpal, J.M.; Joshi, G.C.; Singh, J. Gum forming olefinic precursors in motor gasoline, A model compound study. Fuel Sci. Technol. Int. 1994, 12, 873-894. [CrossRef]

8. Zanier, A. Thermal-oxidative stability of motor gasolines by pressure d.s.c. Fuel 1998, 77, 865-870. [CrossRef]

9. Kinoshita, M.; Saito, A.; Matsushita, S.; Shibata, H.; Niwa, Y. Study of deposit formation mechanism on gasoline injection nozzle. JSAE 1998, 19, 355-357. [CrossRef]

10. Yeh, J.T.; Jou, W.S.; Su, Y.S. Permeation barrier properties of polyethylene/modified blends of polyamide and polyvinylalcohol containers against methanol/gasoline fuels. J. Appl. Polym. Sci. 1999, 74, 2158-2169. [CrossRef]

11. Yeh, J.T.; Huang, S.S.; Yao, W.H. Gasoline permeation resistance of containers of polyethylene, polyethylene/modified polyamide and polyethylene/blends of modified polyamide and ethylene vinyl alcohol. Macromol. Mater. Eng. 2002, 287, 532-538. [CrossRef]

(C) 2017 by the authors. Licensee MDPI, Basel, Switzerland. This article is an open access article distributed under the terms and conditions of the Creative Commons Attribution (CC BY) license (http:/ / creativecommons.org/licenses/by/4.0/). 